Revista Digital Año 8. No 11 - Año 2017. -pág. 1-136

ISSN 1853-1393

Resistencia. Chaco. Argentina - 2017

\title{
RELACIÓN CON LAS FAMILIAS EN LA EDUCACIÓN INFANTIL: TODO DEPENDE DEL CRISTAL CON QUE SE MIRE
}

\section{RELATIONSHIP WITH FAMILIES IN EARLY CHILDHOOD EDUCATION: EVERYTHING DEPENDS ON THE GLASS WITH WHICH YOU LOOK}

Gabriela Alejandra Fairstein ${ }^{1}$

Fecha de recepción: 28-06-2017

Fecha de aceptación y versión final: 29-09-2017

\section{Resumen:}

El trabajo analiza aspectos de la relación entre los educadores y las familias en la educación infantil. Se cuestiona, en particular, si es válido considerar que ambos actúan "como socios". Para ello, se analizan las asimetrías entre institución y familias así como ciertos obstáculos y resistencias a la confianza y valoración mutua. Se entiende que tales condiciones para el trabajo en conjunto no vienen dadas sino que representan un escenario a construir por los educadores. En función de ello, se señala la necesidad de cuestionar las narrativas y los modelos conceptuales a través de los cuales pensamos a las familias y nos pensamos en relación con ellas. Con tal fin, se recuperan dos herramientas de análisis de las prácticas que permiten revisar estas cuestiones: cuatro narrativas acerca de "por qué y para qué las familias envían a los niños al Jardín" y un modelo de triángulo pedagógico para la educación infantil alternativo al que subyace en la escuela básica.

Palabras clave: relación familia-escuela; educación infantil; formato escolar.

\begin{abstract}
:
This paper analyzes aspects of the relationship between educators and families in early childhood education. It is questioned, in particular, if it is valid to consider that both act "as partners". To this end, the asymmetries between institutions and families are analyzed, as well as certain obstacles and resistance to mutual trust and appreciation. It is understood that such conditions for joint work are not given, but represent a scenario to be constructed by educators. Based on this, the need to question the narratives and the conceptual models through which we think about families and think about them is pointed out. To this end, two tools of analysis of practices that allow reviewing these issues are recovered: four narratives about "why and for what families send children to the Kindergarden" and a model of pedagogical triangle for childhood education alternative to which underlies the basic school.
\end{abstract}

Key words: relationship family-school; early childhood education; school format.

\footnotetext{
${ }^{1}$ Lic. Ciencias de la Educación y Tesista de Doctorado (Universidad de Buenos Aires), Mg. Pedagogía Aplicada (Universidad Autónoma de Barcelona), Prof. Educación Preescolar, Guía Montessori AMI. Profesora en la Universidad de Buenos Aires y FLACSO-Argentina, Investigadora UBACyT, Miembro de la Comisión Directiva de OMEP - Argentina, Fundadora de los Jardines Maternales de la Facultad de Derecho de la Universidad de Buenos Aires y del Colegio Público de Abogados de la capital Federal (Argentina). Domicilio: Av. Cabildo 1547 3ero 10. (1426) CABA, Argentina. Teléfono: +5411 47852742. Correo electrónico: gfairstein@gmail.com
} 


\section{Introducción}

En este trabajo nos proponemos continuar con una temática que nos ha ocupado anteriormente: la relación entre educadores y familias en la educación infantil'. Como se analizará, se trata de un aspecto poco atendido de este nivel educativo, a pesar de su relevancia para la tarea. En una primera parte, nos proponemos analizar las condiciones y obstáculos para el desarrollo del tan mentado "trabajo en conjunto entre institución y familia". Como argumentaremos, esta idea descansa sobre algunos supuestos que es necesario revisar para evitar que funcionen como trabas en la comunicación y la co-operación. Esto nos conducirá a prestar atención a las narrativas y modelos conceptuales a través de los cuales se concibe a las familias y se piensa la relación con ellas en la educación infantil. Para ello, en la última parte del trabajo, recuperamos dos herramientas de análisis presentadas anteriormente que han resultado de utilidad para la reflexión sobre tales aspectos: cuatro narrativas acerca de "por qué y para las familias envían a los niños al Jardín" y un modelo de triángulo pedagógico para la educación infantil alternativo al que subyace en la escuela básica.

\section{La relación familia - institución: tan presente como ignorada}

La relación entre la institución y la familia constituye un aspecto sustancial de la tarea pedagógica en la educación infantil pero que suele quedar muchas veces solamente enunciada a nivel declarativo sin ser objeto de análisis y conceptualización específicos (Pulpeiro, 2011; Soto, 2011). Su importancia radica, por un lado, en el hecho de que trabajar en la atención de niños pequeños implica comprender a ese niño o niña en el marco de la familia a la que pertenece. Es decir, nuestro objeto de trabajo es el niño y su familia; lo que sucede en el hogar no es ajeno al educador o educadora infantil. Por otro lado, la propia tarea en educación infantil nos obliga a una comunicación constante con las familias de los niños, ya que ambas agencias institución y familia- nos dedicamos a su cuidado y educación. Ello determina una necesidad de intercambiar información, que se concreta tanto en espacios formales, como cuadernos y reuniones, cuanto informales, como los momentos de entrada y salida del establecimiento.

El lugar que ocupa la relación con las familias en la tarea cotidiana de los educadores infantiles puede apreciarse tanto en términos cuantitativos como cualitativos. Cuantitativamente, alcanza con prestar atención al porcentaje de tiempo que dedicamos a ocuparnos y preocuparnos por cuestiones relacionadas con las familias. Cualitativamente, cabe observar que es este uno de los temas que genera más inconvenientes en el trabajo cotidiano, incluso más que el trabajo con los niños. De hecho, el tema de las familias ocupa un lugar central en las inquietudes que se plantean en reuniones y supervisiones, proporcionalmente mayor al que se le otorga cuando se planifica la tarea. 
Sin embargo, la relación institución - familia constituye un asunto abordado de manera intermitente en los ámbitos de reflexión pedagógica, ya sea en la formación profesional, en los lineamientos oficiales y en la planificación institucional. Si bien hay trabajos importantes en el ámbito académico como el de Siede (2015) y el tema es abordado en documentos curriculares (Moreau y Windler, 2010), el eje se coloca en forma casi exclusiva en el trabajo directo con los niños, lo que conduce a brindar escasa atención a este otro aspecto sustantivo de la tarea pedagógica. De manera que la relación con las familias se aborda mucho más desde el sentido común y las tradiciones institucionales que desde un marco teórico que lo conceptualice. En síntesis, su escasa atención, combinada con su presencia constante sobrevolando la tarea diaria, resaltan la necesidad de trabajar el tema.

En síntesis, la relación con las familias en la educación infantil es una dimensión tan importante como desatendida, un aspecto tan presente como silenciado, y que justamente por eso, irrumpe en la tarea cotidiana, generando preocupación o malestar. Ello conduce a que el tema no sea vislumbrado como relevante y por ende, no sea anticipado en forma suficiente: no se planifica ni se discuten los modos de trabajar con las familias (o se lo hace mucho menos que lo necesario) Obviamente no nos referimos a planificar cuántas reuniones, informes o clases abiertas se realizarán, sino a generar espacios institucionales para pensar conjuntamente aspectos cualitativos de la relación con las familias. Cuestiones como por ejemplo: ¿Cómo se le habla a los padres? ¿Cómo se los escucha? ¿Cómo deben posicionarse los educadores ante las familias? Y yendo más allá, ¿cómo se hace para escapar de la encerrona de juzgarlos o sentirse juzgados?

Estas son algunos de los interrogantes que motivan este trabajo, y si bien no se ofrecerán respuestas acabadas, pretendemos aportar herramientas para pensar esta dimensión de la tarea docente en la educación infantil. A lo largo del texto, nos referimos alternativamente a las instituciones y los educadores, habida cuenta de que esta problemática constituye una cuestión que interesa y que se aborda tanto a nivel institucional como individual.

\section{Rasgos particulares de la relación con las familias en la educación infantil}

Comencemos apuntando algunos rasgos diferenciales de las madres y padres "de infantil", que no hallamos en otros niveles educativos. Como señala Blejmar (2005) las madres y padres "de jardín" son diferentes de los padres "de primaria" o "de secundaria”. ¿En qué aspectos son distintos?

El primer rasgo a destacar es que, con el ingreso de los hijos al sistema educativo, los adultos ocupan por primera vez esta posición institucional. Esto implicará que deben realizar aprendizajes relativos al rol, como, por ejemplo, qué demandas pueden formular y cuáles no, qué expectativas depositar en la institución, qué obligaciones y compromisos deben asumir, etcétera. Pero, como todo aprendizaje 
lleva tiempo, será la etapa de tránsito por la educación infantil el período en que estos adultos estarán familiarizándose con el rol. La consecuencia, entonces, es que las y los educadores de este nivel, a diferencia de sus colegas de primaria o secundaria, trabajan con padres y madres que están ocupando un rol que aún no conocen bien. Incluso, en qué medida la institución debe asumir la terea de acompañar y conducir este aprendizaje es una pregunta que solo aparece en este nivel educativo.

Este es un primer rasgo importante que nos ayuda a entender algunos de los conflictos que suelen suscitarse en educación infantil entre padres y docentes: los educadores esperan, de esos otros adultos, ciertos comportamientos que consideran obvios y naturales; sin embargo, los padres y madres no responden a esta expectativa porque aún no han internalizado las pautas y normas del manejo institucional.

Un segundo aspecto diferencial en la educación infantil, sobre todo en los primeros años, radica en que, familia e institución comparten la tarea, aún cuando este compartir no se haga explícito ni se acuerden los objetivos y principios que la guían. Como señala Mayol Lasalle (2005), "los padres y los educadores comparten la función de socialización en lo atinente a la constitución de modelos de identificación y como portadores de las metas, los ideales y los valores culturales" (op. cit. p. 111). De manera que en la educación infantil, los límites entre los roles educativos de familia y educadores aparecen quizás menos nítidos que en otros niveles educativos.

Ahora bien, este rasgo conduce a que, en la educación infantil, exista el riesgo de una superposición de tareas entre familia y escuela, sobre todo en los primeros años. De hecho, en la escolaridad básica sería posible hablar de una suerte de "división" de la tarea educativa, en virtud de la cual los padres no enseñan en su casa los contenidos escolares (por ejemplo, matemáticas o geografía) En cambio, en la educación infantil encontramos muchas más áreas de aprendizaje en las cuales la tarea educativa de padres y docentes se superpone (por poner solo algún ejemplo, el desarrollo del lenguaje o la adquisición de hábitos de higiene) (Fairstein, 2005b) ${ }^{\mathrm{ii}}$

\section{¿Familia e institución pueden ser socios?}

Estas pinceladas iniciales nos permiten caracterizar a la educación infantil como un espacio en donde la relación familia-institución asume rasgos diferenciales. En aras de dar cuenta de esta especificidad, un modelo explicativo usual entiende que educadores y familia actúan como "socios", principalmente cuanto menores son los niños. El hecho de que se compartan tareas educativas abona esta perspectiva: docentes, junto con padres y madres, co-trabajamos en la educación de los pequeños. Es en virtud de esta labor compartida que los convocamos a reunirnos y nos proponemos aunar criterios entre ambas partes, con mucha más frecuencia que lo que ocurre en otros niveles educativos. 
En un trabajo ya cásico, De León, Malajovich y Moreau (2001) apuntan: "para desarrollar la tarea educativa con los niños, fundamentalmente en estas edades, es preciso que los adultos significativos para ellos, es decir, el docente y la familia, aúnen criterios y esfuerzos [...] Sin embargo, qué ingenuos seríamos si supusiéramos que esta relación está exenta de problemas y conflictos" (op.cit; pp.97)

En las páginas que siguen, pretendemos, justamente, analizar estos obstáculos. Para ello, nos proponemos el ejercicio de cuestionar el modelo explicativo que concibe que institución y familia actúan "como socios". ¿Es la analogía más adecuada para dar cuenta de esta relación, o por el contrario, la idea de "socios" conduce más bien a la confusión de los papeles de cada uno? Anteriormente hemos planteado esta duda, considerando que "esta posición corre el riesgo de establecer una simetría, una equivalencia entre institución y familia que no es tal, desconociendo la clara asimetría que existe entre ellas" (Fairstein 2015; p.29) Vamos a profundizar esta idea a través de interrogarnos por las condiciones que requiere una tarea desarrollada entre socios y por los obstáculos y resistencias que podemos encontrar.

\section{Asimetrías entre familia y escuela infantil}

Al analizar este aspecto, advertimos que estamos proponiendo una asociación, un trabajo en conjunto, entre dos agencias educativas, institución y familia, que son en realidad, muy diferentes entre sí. Si bien ambas se ocupan de la educación, crianza y socialización del niño, encaran este objetivo desde posiciones diferentes y llevan a cabo acciones distintas desde miradas propias. La institución cuenta con conocimientos especializados y experiencia pedagógica, que le permiten actuar de un modo informado y razonado en relación con el niño. En cambio, no pueden darse por supuestas la misma racionalidad y posición informada en las familias - o en cada familia-. Asimismo, también es muy diferente el vínculo de la institución y familia con cada niño en particular así como los derechos y obligaciones que asumen frente a ellos y entre sí. Todas estas cuestiones implican incluso diferencias en cuanto al propio reconocimiento de la necesidad e importancia del trabajo conjunto.

Releyendo el párrafo anterior, lo cierto es que todas estas distinciones parecen bastante obvias y de sentido común. ¿Por qué resulta necesario tematizarlas y analizarlas? Desarrollaremos cada una de estas dimensiones de la asimetría para entender cómo muchas de ellas quedan encubiertas cuando postulamos la idea de que familia e institución actúan como socios.

- $\quad$ asimetría en cuanto a conocimientos y experiencia acerca de cuestiones de educación infantil y crianza. 
La institución y los docentes son profesionales especializados en cuestiones de educación y crianza. Conocimientos provenientes de diversas disciplinas, así como la experiencia acumulada dan cuenta de un caudal para encarar la labor educativa, muy diferente de cómo lo hacen las familias. Si bien este punto es evidente $-y$ no se pretende que las familias posean esta formación- vale la pena resaltarlo porque el sentido común suele abonar posiciones que desvalorizan el conocimiento pedagógico: ya sea cuando se proclama que la crianza de los propios hijos (o nietos o sobrinos) aporta unos saberes superiores como cuando se pregona que "la pedagogía es pura teoría alejada de la práctica". Frente a esto, hace falta recordar y resaltar que la institución y los educadores poseen un saber experto, que proviene no solamente de tematizar la práctica, sino principalmente de desarrollar una reflexión teórica sobre ella.

Es interesante también destacar que este punto casi no es cuestionado en otros niveles educativos. La educación infantil aparece, muchas veces, a los ojos del sentido común, como una tarea más ligada al quehacer doméstico que al profesional. La especificidad y cientificidad de la labor educativa en la primera infancia es un aspecto difícil de visibilizar en la sociedad y por ello, uno de los principales problemas que enfrentamos los educadores a la hora de legitimar nuestra actividad frente a las familias. Esta realidad, lejos de conducirnos a la queja o a culpar a quien sea portador de esta representación, constituye un dato que debe tenerse en cuenta para analizar la relación con las familias en la educación infantil.

De todos modos, es cierto que colocar a la familia y el centro educativo como socios no necesariamente supone ignorar esta asimetría ya que, en una asociación, cada una de las partes podría contribuir de manera diferente a la labor conjunta. Sin embargo, no deja de ser importante destacar la diferencia a efectos de ponderar los aportes de cada actor así como sus consecuencias en relación con los otros planos de la comparación.

- $\quad$ asimetría en cuanto al conocimiento de cada niño en particular

Esta dimensión de la asimetría se refiere a qué lectura y mirada hacen familia e institución sobre cada niño. La afirmación "quien mejor conoce al niño es su mamá" establece a priori unos parámetros muy cuestionables, ya que lo central de la comparación no radica en la cantidad de niños, en el lapso de tiempo que se comparte o en la diversidad de actividades que se desarrollan en cada ámbito. Es la emocionalidad que entraña el vínculo en cada caso lo que establece una diferencia insoslayable entre familia e institución. Si bien esta afirmación resulta obvia cuando se la plantea de esta manera, no parece siempre ser reconocida en la vida cotidiana de las instituciones, cuando se pretende que madres y padres acepten con beneplácito señalamientos relativos al niño o niña. 
La mayor distancia emocional y la menor implicación personal de los educadores ante las problemáticas particulares de los niños es lo que marca una diferencia sustantiva con la familia. Frente a cualquier tipo de situación que se presente en el centro educativo, para madres y padres resulta muy difícil comprender el punto de vista del profesional: no hay más que pensar en los casos en que el niño se lastima o protagoniza una situación de agresión con otro, los cuestionamientos a la atención que a le brindamos, las dificultades para reconocer un problema en el niño, etcétera.

La diferencia en este aspecto resulta entonces mucho más relevante que la anterior. Aquí no se trata de reconocer en el otro unos saberes y experiencia diferentes de los propios. Más bien, la posibilidad de ponerse el lugar del otro para comprender su perspectiva es dificultosa para ambas partes y, en realidad, "casi imposible" en el caso de las familias. Para profundizar esta idea, avancemos hacia la siguiente dimensión.

- $\quad$ asimetría en cuanto a objetividad y racionalidad en la tarea.

Esta dimensión de la asimetría es, en parte, deudora de la anterior y, como veremos, es la que, en verdad, marca la profesionalidad del educador frente a las familias. Una madre o padre puede tener muchos conocimientos (incluso ser profesional de la educación) pero frente a su propio hijo o hija no podrá actuar con la misma objetividad y racionalidad que el educador. Es decir, si bien se comparte la labor educativa hacia el niño, el diferente grado de implicación personal y la distancia que cada uno puede tomar frente a la tarea y al niño determinan una asimetría insalvable.

En el caso de la institución, el conocimiento, la experiencia y la distancia emocional permiten una objetividad y racionalidad en la tarea que la torna cualitativamente diferente de las familias. Incluso frente a la misma tarea desarrollada (por ejemplo actividades de crianza) las familias solamente "las actúan" mientras que los educadores, además, las tematizan y conceptualizan. La institución promueve la reflexión sobre la tarea, lo que permite tomar distancia y analizar las propias prácticas. Incluso, la organización institucional, usualmente jerárquica, genera espacios de supervisión y observación sobre el desempeño, y esto también contribuye a que sea más objetivo y racional.

Pero además la institución no solo puede analizar con mayor objetividad su propia tarea sino incluso comprender cómo la ve la otra parte. Este aspecto es lo que permite a los educadores comprender la perspectiva de las familias: ponerse en el lugar del otro no solo es más factible para el docente, sino que es una exigencia de su 
trabajo y una de sus competencias profesionales. Como decíamos, esta dimensión de la asimetría es la que marca la desigualdad ineludible entre institución y familias: la objetividad y racionalidad en el desarrollo de la labor educativa es, en definitiva, lo que distingue al profesional de la educación. con los niños.

asimetría en cuanto a los derechos y obligaciones en relación

En relación con este aspecto, es obvio que los derechos y obligaciones de familias e instituciones en relación con los menores son claramente diferentes. Queda claro que entre ellas se establece un contrato legal, en virtud del cual asumen obligaciones y adquieren derechos determinados y diferentes para cada una. Sin pretender explayarnos sobre cuestiones legales, probablemente sea esta dimensión la que principalmente nos impide considerar "socios" a la familia y el centro educativo, ya que este tipo de relación es objeto de estudio y regulación en este campo. Desde las ciencias jurídicas, se considera que "los socios están, en la sociedad, en posición de igualdad de deberes y, por consiguiente, de derechos" (Enciclopedia jurídica, s/f)

Pero no hace falta tanto tecnicismo: en la vida cotidiana de las instituciones, la asimetría en la dimensión legal se torna patente toda vez que el centro educativo se erige como garante de los derechos del niño: por ejemplo, cuando los educadores deben actuar frente a situaciones familiares anómalas o en que esté en juego el interés principal del niño. En tales casos, la asimetría es total ya que el centro educativo asume un rol de vigilancia respecto de las familias.

Por último, en virtud de esta asimetría jurídica es que el centro educativo puede imponer y requerir de las familias el acatamiento de determinadas reglas, incluso con la potestad de colocar sanciones (reales o simbólicas) frente a su no cumplimiento. trabajo conjunto.

asimetría en cuanto al reconocimiento de la importancia del

Llegamos así al último aspecto de la comparación. Si considerásemos que centro educativo y familia funcionan como "socios", el primer requisito debería ser que ambas partes estén de acuerdo en ello. Sin embargo, esta es una aspiración de la institución pero no de los padres y madres. Los educadores profesionales reconocen la necesidad e importancia de establecer acuerdos y aunar criterios; las familias no necesariamente lo hacen. Para la institución es un imperativo evitar los mensajes contradictorios y contener los conflictos; los padres y madres pueden no imaginar esta posibilidad. 
En síntesis, las familias no saben que el centro educativo espera de ellos un trabajo en conjunto. Aquí la asimetría vuelve a hacerse evidente, ya que los educadores sustentamos esta idea y pretendemos que se convierta en una aspiración compartida. En este aspecto la asimetría se profundiza: la institución tiene el poder para imponer esta forma de relación. Como señalamos antes, en función del contrato implícito con las familias, el centro educativo tiene la facultad de convocar a las familias y requerir su participación institucional, e incluso de sancionarlas si no lo hacen.

Por último, además de la intención y el poder de convocar, la institución tiene las herramientas para conducir la acción conjunta: sabe qué y cómo hacer para lograrlo. El centro educativo puede proponerse en forma explícita o no el lograr que padres y madres comprendan la importancia de co-operar. Pero en cualquier caso, sea como objetivo institucional o no, será tarea de los educadores lograr que la idea de ser socios en la educación de los niños se convierta en una aspiración compartida y que las familias efectivamente colaboren en el desarrollo de la tarea en común.

\section{Resistencias y obstáculos para el trabajo conjunto entre institución educativa y familia}

Pasaremos ahora a analizar una segunda cuestión: una provechosa "asociación" para el trabajo en conjunto supone que este se apoye en la confianza mutua y valoración de la acción de la otra parte. Sin embargo, esta es una condición difícil de cumplir y la experiencia pone de manifiesto importantes resistencias y obstáculos. Entre ellos señalemos los siguientes:

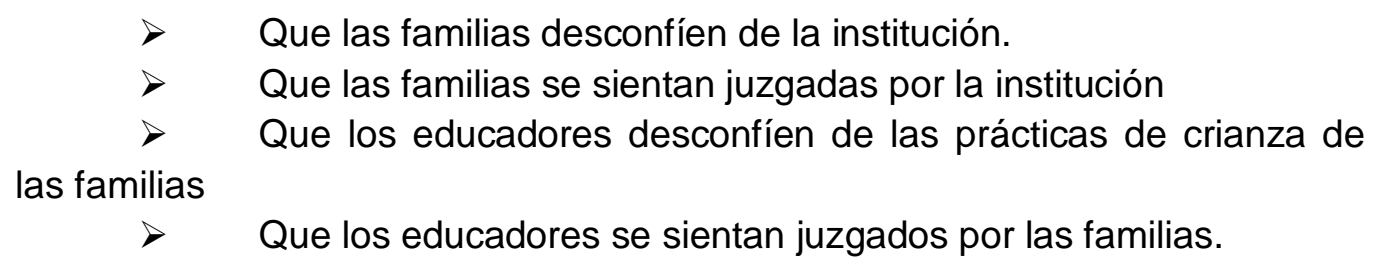

Analizaremos cada uno:

- que las familias desconfíen de la institución.

La desconfianza de las familias hacia los centros educativos constituye un fenómeno habitual, que ha acompañado el desarrollo de la institucionalización de la educación desde sus orígenes, pero que se ha profundizado en las últimas décadas. 
Diversos son los factores que contribuyen hoy en este punto, entre ellos, la crisis del formato escolar moderno, la desvalorización de la figura docente, el debilitamiento general de la credibilidad en las instituciones. Por otra parte, la proliferación de denuncias de abuso y situaciones de violencia en los centros educativos, amplificadas por los medios de comunicación y las redes sociales, son otros elementos que aportan a ahondar aun más el fenómeno.

Sin embargo, la desconfianza de las familias hacia la institución educativa no es un dato reciente sino que parece ser un rasgo inherente al propio vínculo. Según los especialistas, esta relación se ha configurado históricamente al calor del propio proceso de institucionalización de la educación. Desde la antropología, Neufeld (2010) sostiene que el vínculo padres- docentes ha estado signado desde sus orígenes por una suerte de "vigilancia mutua", que gobierna los intercambios y las expectativas mutuas. Tanto unos como otros desconfían de la otra parte, en aspectos que van desde sus competencias hasta su calidad moral. Por su parte, Pineau (2001) ha señalado que el proceso de configuración de la escuela moderna trae aparejada, como un resabio de la educación eclesiástica, la representación del educador como un ser idealizado -ejemplo de conducta, la "maestra inmaculada"-.Esta imagen generaría que todo docente real, que se aleja necesariamente de ese ideal, sea objeto de críticas.

Desde una perspectiva psicológica, Defey (2000) analiza el fenómeno haciendo referencia a la rivalidad entre padres y educadores por el amor del niño: "Parecería que una madre que se precie inevitablemente tiene que encontrar algo para criticar en quien comparte el cuidado y crianza del niño. Parecería que un educador que se precie debe estar siempre alerta al fantasma del «rechazo» de los padres respecto al niño. Con el tiempo, uno llega a comprender que esa cierta rivalidad es casi inevitable y responde a los intensos sentimientos y procesos de apego que genera el contacto con niños muy pequeños y que, en definitiva, también tiene un aspecto de protección el hecho de que haya más de un adulto que anhele tener un papel fundamental en la crianza del niño" (op. cit. p. 49)

Pero no por cotidiana y conocida, la conflictividad inherente al vínculo representa un obstáculo fácil de abordar, que además se profundiza cuanto menor es la edad de los niños. En relación con la educación infantil en particular, esta se manifiesta de diferentes maneras: como desconfianza en los beneficios y conveniencia de que los niños asistan a un centro de educación infantil, como desconfianza en la capacidad profesional de los educadores e incluso como desconfianza en su integridad moral. Por ejemplo, en una investigación desarrollada en Buenos Aires, Soto y Violante (2005) encontraron que el jardín maternal es considerado como un "mal necesario" por una porción de padres y abuelos de los niños. Por su parte, Mayol Lasalle (2005) ha observado que el ingreso de los niños y bebés al centro educativo "se ve perturbado por los prejuicios y por cierto rechazo social a esa institución" y que las familias no parecen seguras de esta constituya una buena alternativa (op. cit. p. 104). 
- que las familias se sientan juzgadas por la institución.

La fantasía y el temor de ser juzgados por los educadores en su calidad de padres constituyen otro obstáculo muy frecuente para establecer una relación provechosa entre familias e institución. También se trata de un fenómeno inherente al vínculo, acrecentado por problemáticas culturales actuales y más pronunciado cuanto menor es la edad de los niños

En la educación infantil, Mayol Lasalle (2005) señala que "muchos padres, en especial las madres, se sienten juzgados por las maestras, lo que acrecienta su ansiedad hasta hacerla insoportable. El equipo de conducción y las docentes del jardín maternal deberán entonces desarrollar una actitud reflexiva y empática, evitando constituirse en jueces de los padres y tranquilizando especialmente a la madre respecto de sus "competencias maternales", su interés por el niño y el protagonismo de su rol." (op.cit; p.134) Por su parte, un estudio desarrollado en Montevideo por Betancur (2000) también encontró niveles muy bajos de participación de los padres en los jardines maternales, para no exponerse frente a los educadores.

Este recelo y temor de ser juzgados por la institución responde, por un lado, a los rasgos del propio vínculo. En esta línea Silvia Silberman (2010) señala que el inicio de la escolaridad de los hijos remite a los adultos a su propia experiencia escolar. La institución educativa es un ámbito cargo de juicios y evaluaciones, de modo que "volver a la escuela", si bien en el rol de padres y madres, reedita el temor y la incertidumbre vividos en la propia infancia.

Pero por otro lado, en la actualidad esto se liga con una sintomatología cultural que excede a la relación con las instituciones educativas. Las dificultades para ocupar los roles parentales, así como para asumir las responsabilidades que implican la maternidad y paternidad, constituyen un elemento central a considerar cuando se analiza el fenómeno. En los últimos años, asistimos a cambios culturales en relación con el ideal de maternidad y paternidad, que generan mayores exigencias a los adultos, al punto de tornarlos inalcanzables. Esto afecta la relación con los educadores dado que "son vistos como los guardianes de ese ideal, aquellos que van a poder detectar si los padres cumplen o no lo que se espera de ellos". (Defey, op. cit. p.54) En una línea similar, Hochstaet (2011) analiza las dificultades que enfrentan hoy los padres y destaca la falta de pautas claras y estables, la ausencia de interlocutores válidos para estos adultos en ese nuevo rol. Además, los medios de comunicación brindan consejos y orientaciones idealizadas y recortadas de la realidad, que cambian al ritmo de los intereses del mercado. En este marco, los educadores son vistos como fiscales (Hochstaet, 2005)

familias

- que los educadores desconfíen de las prácticas de crianza de las 
Frente al temor de madres y padres de sentirse juzgados, es cierto que no es tan infrecuente que los educadores se posicionen en jueces respecto de las familias. Si bien hay acuerdo en que la institución debe partir de la aceptación y respeto a las prácticas familiares, esto no siempre sucede, incluso a pesar de las buenas intenciones. Es decir, desde lo declarativo se sostiene la importancia de valorizar a padres y madres en su rol, pero desde las actitudes se transmite una mirada descalificadora. En este sentido, cuando los educadores se quejan de los padres que "les tocaron" -por ejemplo, que son "abandónicos", que "depositan al niño y se desentienden de su educación"- se están erigiendo en jueces de las familias.

Este fenómeno conduce a prestar atención a las representaciones de los educadores acerca de cómo deberían actuar las familias y acerca del rol del centro de educación infantil hacia ellas. Estas expectativas e imágenes internalizadas son las que actúan, a nivel inconsciente, orientando la acción.

Las expectativas de los educadores hacia las familias y lo que consideran tarea de cada uno son una fuente habitual de trabas y dificultades en la relación con los padres. En este sentido, Marotta (2011) señala que en educación infantil "se producen "zonas de conflicto", entre aquello que esperan y desean los padres para sus hijos y aquello que las maestras están en condiciones de brindar y consideran que hace a su tarea" (op.cit. p. 73). En un línea similar Nicastro (2011) explica que los malosentendidos responden a que los educadores atribuyen a las familias una comprensión similar a la propia: "A veces creemos que decimos rutina, y ya todos sabemos de qué hablamos, que decimos período de inicio y con sólo contarlo ya el otro entendió y aceptó" (op.cit. p. 14).

Las imágenes internalizadas acerca del ideal de familia también actúan generando actitudes reprobatorias hacia las familias reales. En este sentido, Defey (200) se refiere a la "patología de la idealidad" para explicar que, al igual que los padres, también los educadores están atravesados por modelos culturales idealizados de padre y madre. Estos modelos internos funcionan implícitamente como parámetro de comparación, de manera que las familias concretas quedan desvaloradas en relación con el ideal. En este sentido, el educador se erige en juez de las familias, cuando idealiza un tipo de familia y se queja de los padres que "les tocaron".

- que los educadores se sientan juzgados por las familias.

Este último fenómeno es más difícil de reconocer pero también se trata de una problemática presente en los centros de educación infantil. Este se explica, por un lado, como contracara del primero que mencionamos, la desconfianza de las familias hacia la institución. En segundo lugar, debe atenderse a ciertos efectos que suele 
producir el trabajo con niños pequeños en relación con la emocionalidad de los adultos. Ambos factores contribuyen a explicar la posibilidad de que, en mayor o menor medida, los educadores sientan temor de ser juzgados por esos otros adultos que son los padres y madres de los niños.

En este sentido, hemos mencionado que la relación entre los educadores y las familias está cargada de suspicacias y recelos respecto del otro. La "vigilancia mutua" y la rivalidad entre padres y educadores, mencionada más arriba, generan un cierto estado de alerta permanente frente a los potenciales "ataques". La posibilidad de que esto genere en el educador una sensación de indefensión y temor dependerá tanto de su profesionalidad como de la contención y apoyo que pueda brindarle la institución.

Asimismo, la patología de la idealidad abordada anteriormente, puede conducir también a la sacralización de los padres y madres de los niños, colocándolos en un lugar de superioridad. La idea de que "ellos saben mejor que nadie lo que es bueno para sus hijos", coloca a los educadores en una posición de subordinación. Ver a las familias como portadores de la verdad con respecto al niño, implica que los docentes se sientan juzgados por ellos.

Esto se relaciona a su vez con la segunda cuestión mencionada: la referida a las emociones que despierta en los adultos el trabajo con niños pequeños y con bebés. En este sentido, puede producirse una identificación con las madres y padres, sobre todo cuando aquellos no están seguros de la decisión de enviar al niño al centro educativo. En tales casos, los propios educadores parecen cuestionar la conveniencia y beneficios de la institución, considerando que se expone a los niños a una institucionalización demasiado temprana. En este sentido, Mayol Laasalle (2005) ha encontrado, en el personal de los jardines maternales, inseguridad y sentimientos de culpa motivados en esta idea.

Por último, en relación con los efectos emocionales del trabajo con niños pequeños, también puede producirse identificación con los niños, lo que genera una re-edición de temores de la propia infancia (Mayol Lassalle, 2005; Fernández, 1994; Pulpeiro, 2011) Esta cuestión está relacionada con la fantasmática o fantasías inconscientes que actualiza en los adultos la labor en la atención de bebés y niños. En esta línea Hochstaet (2005) señala que esta identificación conduce a la impotencia frente a las críticas de los padres y a que estas sean vividas evocando a los propios padres infantiles, de quienes se espera aprobación y reconocimiento.

\section{La paradoja de la relación institución- familia en la educación infantil}

Las asimetrías entre familia e institución así como el análisis de los obstáculos y resistencias ponen de manifiesto que las condiciones para el desarrollo de un trabajo en conjunto no se dan en forma "natural", que no vienen dadas. Por el contrario, el análisis de las asimetrías ha mostrado que se trata, más bien, de una aspiración de la 
institución, por lo que serán los propios educadores quienes deban construir el escenario para hacerlo. Como hemos señalado otras veces, "los padres no fueron al profesorado".

De esta manera, entendemos que, en la educación infantil, las familias ocupan una doble posición:

Como co-laboradores:

$>$ familia e institución comparten la tarea educativa que se desarrolla hacia el niño.

Como destinatarios:

$>\quad$ la institución brinda orientación a las familias para el desarrollo de la tarea en conjunto.

Lo cierto es que estos dos objetivos entran en tensión y plantean una paradoja. Por un lado, la institución debe colocarse a la par de las familias, lo que supone un vínculo relativamente simétrico. Pero a la vez, los educadores deben situarse en una posición pedagógica, lo que implica de por sí una relación de asimetría (Meirieu, 1998) Anteriormente hemos planteado esto como un dilema: “incluimos a los padres como sujetos de educación (educandos) y planificamos para ellos, o los colocamos a la par nuestra y les pedimos que aúnen criterios con nosotros? ¿En el primer caso, los igualamos al niño? ¿En el segundo, les demandamos una racionalidad que a lo mejor no pueden tener?" (Fairstein, 2005b; p. 25)

Esta cuestión resume lo que, en otro trabajo, hemos denominado la paradoja de la relación con las familias en la educación infantil: "Los dos objetivos pueden entrar en contradicción si no se los maneja de manera reflexiva, y con extremo cuidado y seriedad. En muchas ocasiones, el péndulo se inclina para alguno de los lados de la paradoja y el centro educativo termina no logrando llevar adelante sus intenciones". (Fairstein, 2011. p.83)

En función de estas consideraciones, entendemos que resulta central examinar el modo en que el centro educativo infantil se posiciona frente a las familias. Sin embargo, como señalamos al comienzo, esta cuestión es abordada de manera tangencial en la formación y en la planificación institucional. Ello conduce a que los educadores encuentren pocos espacios para confrontar las representaciones del sentido común que circulan en torno del tema así como para analizar los modelos conceptuales que subyacen en su explicación.

En función de estas consideraciones, en lo que sigue, nos proponemos compartir dos herramientas de análisis que permiten revisar los modos de pensar y pensarnos en relación con las familias en educación infantil. Si bien han sido elaborados en relación con el jardín maternal, sus planteos permiten analizar esta cuestión en la educación infantil en general. 


\section{Centros de educación infantil ¿compasivos, reparadores, a medida, terapéuticos?}

En trabajos anteriores (Fairstein 2005a; 2011) hemos elaborado un conjunto de cuatro modelos que representan distintas "narrativas" desde la cuales se suele entender la relación entre las familias y los educadores de infantil. Hemos presentado estos cuatro modelos como una hipótesis de trabajo, que funcione como herramienta para que los educadores de infantil puedan utilizarlos para el análisis de las prácticas. Como se verá, cada tipo apunta a modelizar ciertas representaciones del sentido común que suelen actuar en forma implícita entre los educadores, es decir, cada uno constituye una narrativa acerca de la relación institución - familia en la educación infantil. Fueron construidos a partir de la observación de prácticas cotidianas en centros educativos, pero han sido relativamente "estereotipadas" o "exageradas" a efectos de poder analizarlas.

Los modelos se definen en relación con dos cuestiones: cómo se posicionan los educadores infantiles frente a las prácticas de crianza desarrolladas en el hogar, y cómo asumen los roles tanto de contener como de orientar a padres y madres. Si bien estas narrativas no pretenden contemplar todas las posibles comprensiones de la relación familia-institución y no necesariamente se presentan en forma pura en la realidad, representan un espejo para mirarnos y examinar nuestros modos de pensar a las familias y pensarnos en relación con ellas.

Los cuatro modelos de narrativas son:

- Modelo "compasivo": se evidencia cuando los educadores parecen sentir pena por las familias por tener llevar a los niños al centro educativo. En estos casos, no se logra contener el sufrimiento real que provoca la separación, sino que se lo acrecienta. Asimismo, se dificulta que la institución pueda posicionarse en un lugar educativo hacia las familias ya que queda desvalorizada.

- Modelo "reparador" o "salvador": se percibe cuando se considera que los padres "depositan" al niño y se desentienden de su educación, y la institución aparece en una tarea reparadora o salvadora. En tales situaciones, la institución se relaciona con las familias desde un lugar reprobatorio y por ello mismo tampoco puede ofrecer contención ni orientación.

- Modelo "como en casa" o "a la carta": se observa cuando se entiende a la educación infantil como un servicio a la medida de cada familia, bajo la idea de que son quienes mejor conocen al niño. La institución considera que debe adecuarse a las prácticas de crianza familiares. De manera que 
este modelo si bien no descalifica a las familias también ve limitada su función de orientación.

- Modelo "terapeuta familiar": se manifiesta cuando la institución, si bien reconoce y asume su función de contención y orientación, percibe a padres y madres como inexpertos o limitados. El centro educativo se coloca en un lugar superior, rebasando sus funciones y desestimando los saberes y prácticas familiares.

El siguiente esquema resume los cuatro modelos:

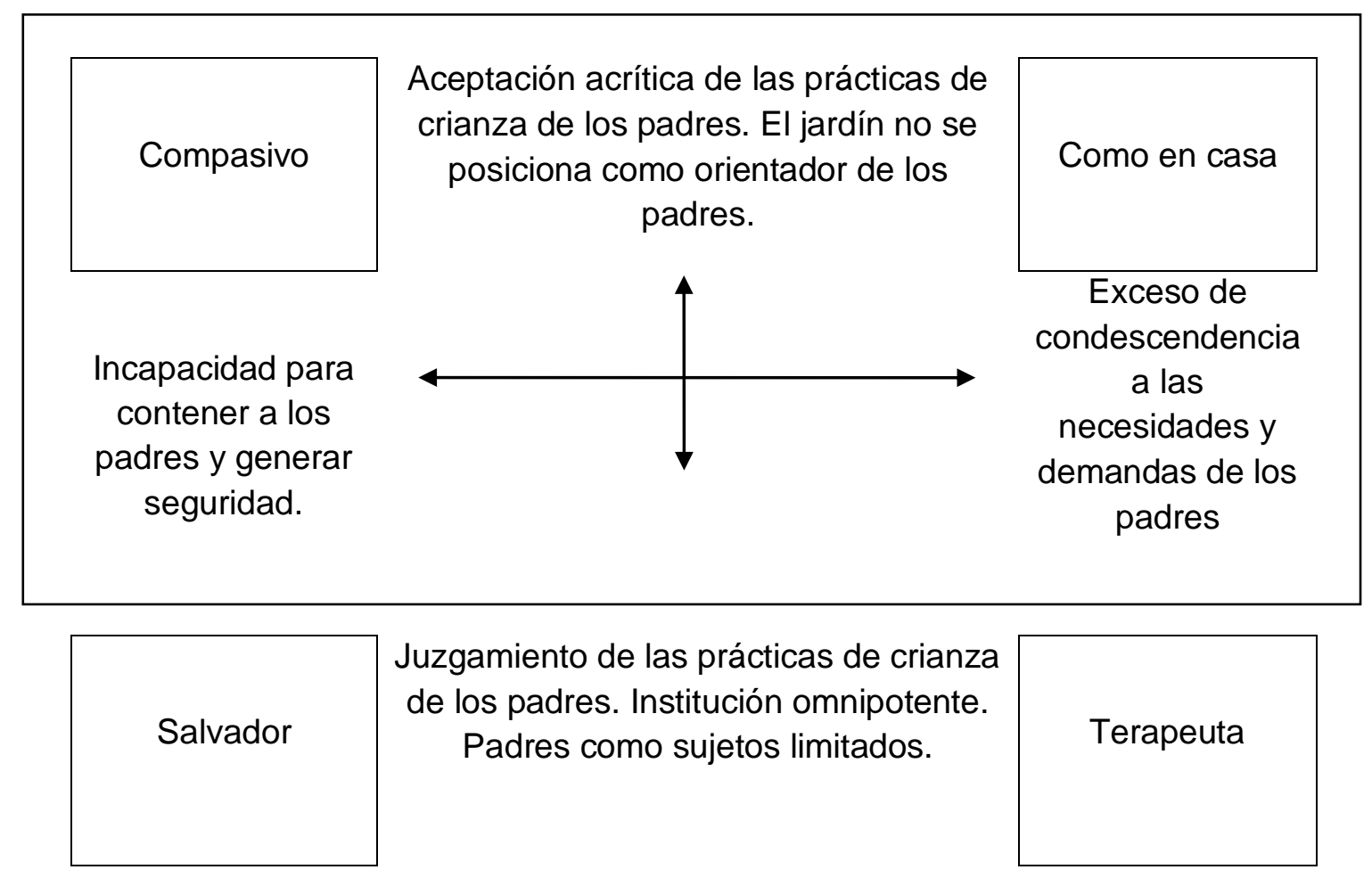

(adaptado de Fairstein, 2011)

Como señalamos, estas narrativas no agotan todas las posibles imágenes sobre el vínculo familia - institución, pero pueden funcionar como hipótesis para analizar las modalidades que asumen las instituciones frente a la tensión de la paradoja: entre la necesidad de un trabajo conjunto entre educadores y familia, y el objetivo de orientar a los padres en su rol. Sin dudas, las instituciones se definen desde diversas dimensiones de modo que esta clasificación solo tiene sentido a efectos de analizar esta cuestión en particular.

Por último, fue nuestra intención presentar un conjunto de modelos en donde ninguno apareciera como "el mejor". Consideramos que cada uno tiene elementos valiosos y otros muy cuestionables. En los cuatro casos, los modelos recogen vivencias y percepciones reales de los educadores, como por ejemplo, la empatía con las familias, la desazón frente a la falta de compromiso, la necesidad de adecuarse a los casos particulares o la percepción de que la institución puede advertir obstáculos 
en las dinámicas familiares. El problema radica, a nuestro entender, en los marcos de sentido y conceptuales desde los cuales se interpreta el vínculo familia- institución, cuando estos conducen a lecturas parciales y pueden terminar obstaculizando la tarea. En síntesis, el valor de estos modelos estriba en su potencial para funcionar como herramienta de análisis de estas representaciones del sentido común, que es inevitable (y es esperable) que surjan en el trabajo en educación infantiliii.

\section{El triángulo pedagógico en la educación infantil}

En el apartado anterior hemos cuestionado los marcos narrativos o de sentido desde los cuales se interpreta el vínculo con las familias. Para finalizar, abordaremos a continuación un examen del marco conceptual que usamos para entender esta relación. Es decir, pasaremos a otro plano de análisis, donde discutiremos el modelo explicativo que subyace detrás de nuestra comprensión del vínculo con las familias. El interés por examinar este esquema conceptual deriva de interrogarnos si acaso este no ha sido exportado del modelo escolar, sin adecuarlo a las especificidades de la educación infantil.

En este sentido, Pineau (2001) señala que el formato escolar se convirtió en sinónimo de "pedagógico", de modo tal que subordinó al resto de las prácticas educativas. En esta línea Terigi y Perazza (2006) consideran que la historia del nivel inicial ha traccionado a la educación infantil hacia el formato escolar y que uno de los rasgos que mayor revisión amerita es el relativo al modo de concebir la relación con las familias. Por nuestra parte, hemos señalado que el esquema conceptual que explica la relación con la familia en otros niveles educativos no resulta adecuado en educación infantil (Fairstein 2005b ${ }^{\text {iv }}$ )

En un trabajo previo (Fairstein, 2005b) propusimos analizar el vínculo entre familias y educadores a través de reformular el triangulo pedagógicov que explica las diferentes relaciones educador-aprendiz-objeto. En este sentido, hemos señalado que, en la escuela básica, este triángulo se redefine como relación entre "docente-alumnocontenido curricular", que se diferencia claramente de la relación "familia-hijosocialización o crianza". La "inter-relación" entre familia y docentes se apoya en forma implícita en este modelo. 
El siguiente gráfico esquematiza la interrelación:

\section{INTERRELACIÓN FAMILIA- EDUCADOR EN EL FORMATO ESCOLAR}

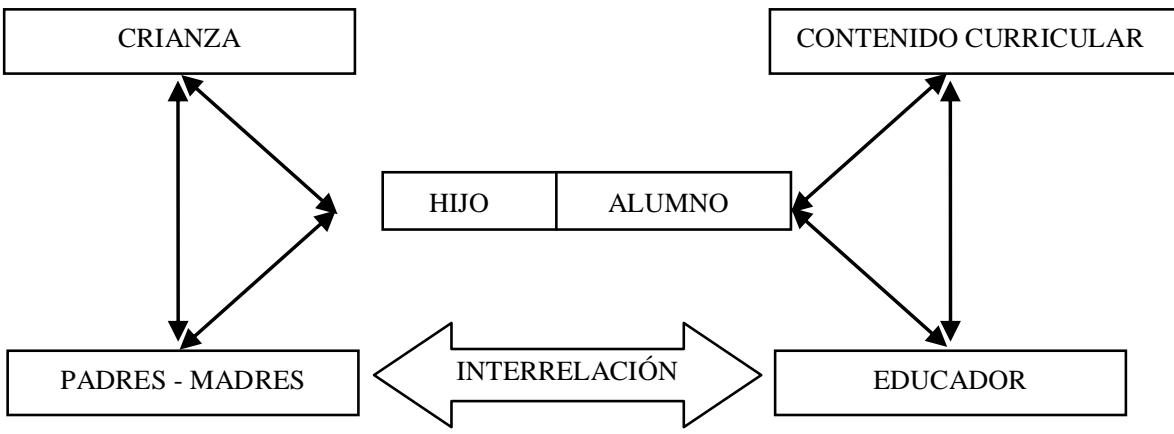

(esquema adaptado de Fairstein, 2005b)

En el trabajo mencionado hemos cuestionado si estas diferencias son tan nítidas en educación infantil como para considerar válido este esquema, o si por el contrario, ameritan revisar su adecuación.

En cuanto al "objeto", en la educación infantil, la crianza y la socialización se constituyen en contenido curricular (Soto y Violante, 2010; Zabalza, 2000). De modo que este componente marcaría diferencias menos nítidas entre los dos triángulos, en comparación con la escuela básica. Por supuesto, ello no impide considerar como contenidos curriculares a los conocimientos de la educación infantil, en la medida en que han sido objeto de procesamiento didáctico - una selección, secuenciación y organización- a efectos de elaborarlos en un marco curricular ${ }^{\mathrm{vi}}$. Pero en cuanto a su objeto general, la crianza es una acción educativa desarrollada tanto por los docentes como por las familias. Sin dudas, y como ya hemos señalado en este trabajo, las acciones de ambos se diferencian desde otros aspectos, como la amplitud en los escenarios de aprendizaje, el abanico experiencias que pueden ofrecer, el carácter de la intervención pedagógica, el tipo de estimulación, etcétera, además de la profesionalidad e institucionalización, en los casos que corresponda. Como hemos apuntado ya, el educador posee un conocimiento especializado acerca de la primera infancia y las prácticas de crianza, que le permite actuar de un modo más informado, racional y objetivo.

En cuanto al componente "aprendiz", la distinción entre los dos triángulos en el modelo escolar se define desde el rol diferente que el niño asume en cada caso. Sin embargo, al analizar la educación infantil advertimos que la capacidad psicológica de asumir roles y reconocerse en ellos no puede atribuirse a los niños pequeños. Si el 
"ser alumno" constituye "un efecto particular de las prácticas escolares" (Baquero, 1996), un "oficio" que se aprende a través de la cultura escolar (Perrenoud, 1991) en la educación infantil no podemos hablar de "alumnos" en ese sentido.

Pero, ¿podemos definir al aprendiz como "el niño"? En realidad esta definición también sería cuestionable. En los primeros años de la educación infantil, en los que se trabaja con bebés y menores de tres años, el niño se halla en un estado de indiferenciación psicológica respecto de su madre. En este sentido, se ha sugerido que el lugar del aprendiz está ocupado por la díada bebé-mamá (Gutman, 2001) En los siguientes años de la educación infantil, la idea de bebe-mamá es reemplazada, pero aun así la tarea educativa se dirige hacia esa constelación que constituye el niño con su familia.

Estas consideraciones nos llevaron a elaborar un nuevo esquema para comprender las relaciones entre el triángulo pedagógico del docente y el de las familias en la educación infantil:

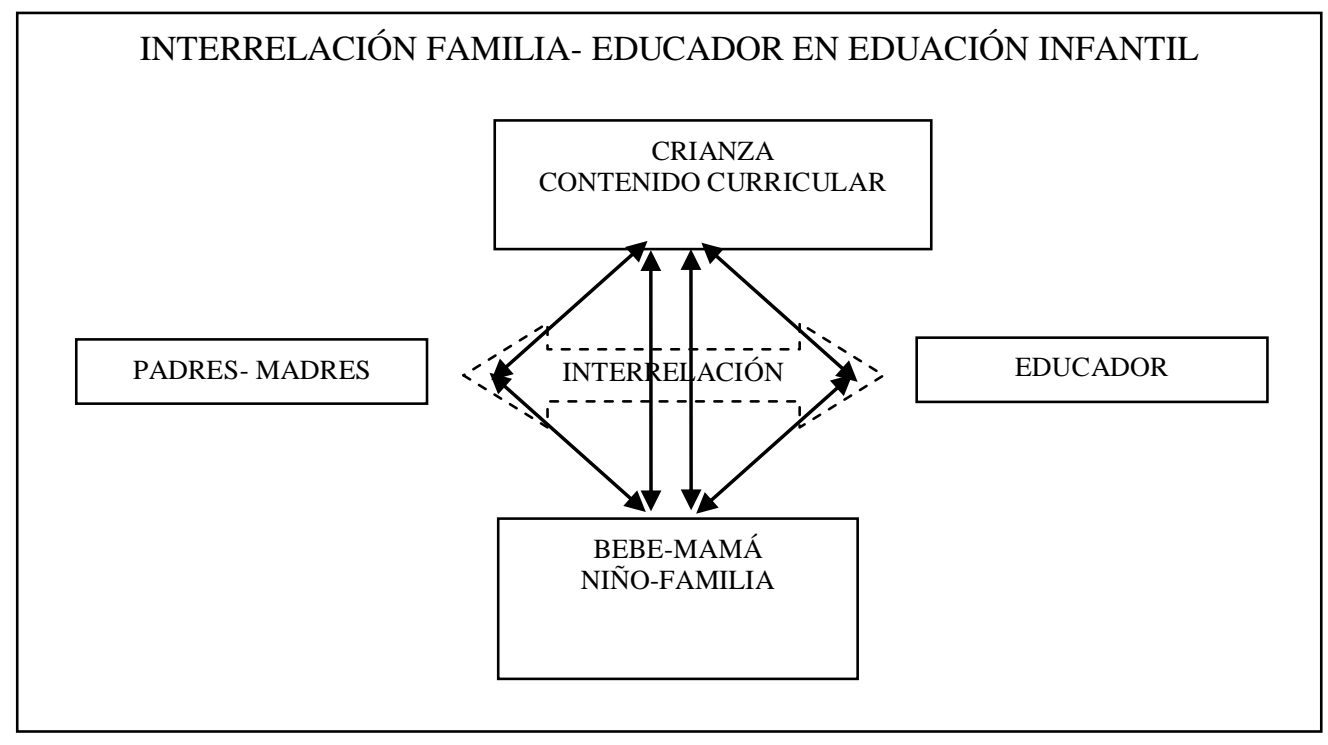

(esquema adaptado de Fairstein, 2005b)

El esquema presenta dos triángulos diferentes, al igual que en el modelo escolar: el de los padres y el del docente. Pero los dos triángulos se encuentran superpuestos en uno de sus lados ya que ambos desarrollan acciones sobre el mismo "aprendiz" y con objetos coincidentes (si bien, como ya señalamos, encaran este objetivo desde posiciones diferentes y llevan a cabo acciones distintas) La presencia de la mamá o de la familia formando parte de dos elementos (aprendiz y educador) da cuenta de la complejidad de la relación con las familias. La tarea del educador se dirige hacia el "bebemamá" o hacia esa constelación que forma el niño con su familia, pero no hacia el niño disociado de esos vínculos. 
Confrontado con el esquema del modelo escolar, aquí la interrelación entre padres y docentes no es externa sino interna a la relación con el "aprendiz" y con el "objeto": ello se observa en la línea punteada que atraviesa por dentro a los dos triángulos (y que, en el otro caso, está colocada afuera) En el modelo escolar se establece una interrelación entre dos relaciones diferentes. La escuela prioriza la relación docente-alumno, y se concibe a la relación padres-hijo como un elemento que puede obstaculizarla o facilitarla. En el caso de la educación infantil, los dos triángulos no se diferencian del mismo modo ni se relacionan del mismo modo.

Por otro lado, en el modelo del formato escolar, familia y educadores se diferencian no solo en el vértice que corresponde al componente "educador". La distinción entre "contenido curricular" y "crianza" así como la asunción del rol institucional de "alumno" por parte del niño, también confluyen para marcar y legitimar las diferencias entre la acción de cada parte. Sin embargo, en educación infantil, estos dos componentes contribuyen menos a marcar la divergencia. El peso de la diferencia recae principalmente sobre la distinción entre docentes y familias.

En síntesis, este esquema -que sin dudas puede mejorarse- aspira a explicar la interrelación entre familias y educadores en la educación infantil desde una lógica diferente del modelo escolar. Lo hemos elaborado a título de ensayo, no para cerrar sino más bien para abrir la discusión teórica. Se nos podrá objetar que, más allá de las teorías, en la práctica, los buenos educadores de infantil se manejan con las familias de manera clara y fructífera. Estamos de acuerdo. "No obstante ello, consideramos importante compartir estas reflexiones ya que la teoría que se usa no sólo le pone nombre a lo que hacemos; también configura nuestro modo de pensar sobre ello" (Fairstein, 2005b, pp.25)

Profundizar en este esquema conceptual alternativo excedería los límites de esta presentación (y ha sido desarrollado en extenso en el trabajo mencionado) vii Solo nos interesaba poner en evidencia el marco explicativo que subyace en el modelo escolar para la comprensión de la relaciones familia- educadores. $Y$ advertir que cuando utilizamos en forma implícita este mismo esquema en la educación infantil, corremos el riesgo de analizar la cuestión desde un marco poco adecuado. Como hemos señalado, "el que a veces nos cueste entender por qué algunos padres no saben ubicarse, a lo mejor obedece a que lo pensamos desde un modelo conceptual inadecuado" (Fairstein, 2005b, pp.25)

Por último, si el peso de la diferencia recae principalmente sobre la distinción entre docentes y familias, si los componentes 'objeto' y 'aprendiz' contribuyen menos para diferenciar y legitimar la acción de los educadores frente a las familias, se justifica aún más la importancia marcar las asimetrías entre ambos. Sin embargo, como hemos visto, la idea de socios corre el riesgo de encubrir, en lugar de resaltar, esas diferencias.

\section{A modo de cierre}

En este trabajo nos interesó analizar la relación con las familias en la educación infantil. Hemos señalado que se trata de un aspecto menos atendido que 
otros en la literatura pedagógica del nivel. Entre las posibles causas de ello, hemos señalado que se entiende que el centro de atención lo constituye el trabajo con los niños. Sin embargo, luego de este análisis cabe también cuestionar esta afirmación.

En educación infantil, y sobre todo en los primeros años, cabe cuestionar si es correcto considerar solamente a los niños como destinatarios de la tarea del educador. De hecho, los programas educativos para la primera infancia se definen no solamente por el trabajo directo con los niños sino que se plantean objetivos pedagógicos en relación con los padres y madres (Peralta, 2005; Mayol Lasalle, 2005; Soto, 2011; Waldmann, 2011)

En este sentido, tomar en serio el lugar que ocupa la relación con las familias en la educación infantil requeriría mucho más que un reconocimiento formal de su importancia: supone, más bien colocar en un lugar completamente diferente a la cuestión tanto en la formación profesional como en la planificación curricular e institucional. La relación con las familias ocupa, actualmente, no mucho más que una unidad didáctica en algunas materias de la formación profesional y un apartado accesorio al cuerpo central de diseños curriculares y proyectos institucionales.

Sin dudas, ello supone una redefinición de las propias competencias profesionales de la educación infantil, que contemple en un lugar de relevancia al trabajo con adultos o adolescentes en el rol de padres y madres. Ello permitiría discutir y planificar, desde la política educativa, la provisión de herramientas conceptuales e instrumentales para esta tarea. De lo contrario, se sigue manteniendo librada al sentido común una importante proporción de la labor de los educadores de infantil, con las consecuentes dificultades que acarrea. Incluso es de prever que este aspecto requiera ser atendido aun más en el futuro, a partir del reconocimiento legal de nuevas configuraciones familiares

\section{Bibliografía:}

Baquero R. (1996), Vigotsky y el aprendizaje escolar. Bunos Aires, Aique.

Basabe, L., Cols, E. y Feeney, S. (2004), Los componentes del contenido escolar. Ficha de Cátedra. Buenos Aires, OPFYL, Facultad de Filosofía y Letras, Universidad de Buenos Aires.

Blejmar, B. (2005), Gestionar es hacer...que las cosas sucedan. Competencias, actitudes y dispositivos para diseñar instituciones. Buenos Aires, Noveduc Libros.

Camilloni, A. (2014), Las metáforas conceptuales en la construcción del discurso pedagógico. Revista de Educación, 5, 7,17-32

Coll, C., Pozo., J.I., Sarabia, B. y Valls, E. (1994), Los contenidos de la Reforma. Buenos Aires, Santillana, Aula XXI.

De León, A., Malajovich, A. y Moreau, L. (2001): Pensando la educación infantil. Buenos Aires: Octaedro.

Defey, D. (2000), "Ser padres y ser educadores hoy". En Organización Mundial de la Educación Preescolar (OMEP), El Jardín Maternal, un desafío para el siglo XXI. Ecos 
nacionales del I Congreso internacional de Educación en Jardín Maternal del MERCOSUR. Montevideo, 49-54)

Enciclopedia jurídica (s/f): http://www.enciclopedia-juridica.biz14.com/d/socio/socio.htm Fairstein, G. (2005a), "La relación entre la familia y el Jardín Maternal. Algunos modelos para el análisis", Revista Novedades Educativas, 177, 20-23.

Fairstein, G. (2005b), “¿Cuál es la diferencia entre lo que hacen los docentes de Maternal y lo que hacen los padres? Un análisis del modelo teórico para interpretar la relación pedagógica en Jardín Maternal". Revista virtual e-Eccleston. Estudios sobre el nivel inicial, Año 1, N 1, Recuperado de: http://iesecclestoncaba.infd.edu.ar/sitio/upload/Revista N1.pdf (17/11/ 2017)

Fairstein, G. (2009), "«Que el niño logre... ¿Y si el niño no logra?» Problemas y paradojas de la planificación didáctica en Jardín Maternal”. En M. Mayol Lassalle (comp.), Grandes temas para los más pequeños. Acerca de la complejidad de la educación en los primeros años. UNESCO - OMEP. Buenos Aires: Ediciones Puerto Creativo.

Fairstein, G. (2011): “¿Son víctimas, son abandónicos, son nuestros patrones o nuestros pacientes? Modelos para pensar relación familia - institución en la educación de la primera infancia". En OMEP (Coord) Educación Infantil. Estudios y prácticas. Volumen II. Buenos Aires, OMEP - 12ntes, 81-94.

Fairstein, G. (2015): "Relaciones entre adultos en el jardín de infantes" Revista Novedades Educativas, 296, 26-30.

Fernández, L. (1994), Instituciones educativas. Buenos Aires, Paidós

Gutman, L. (2001): "Maternar bebés ajenos en el jardín maternal", en Revista Novedades Educativas 0 a 5.La educación en los primeros años, Año 4, N 35, 76-91.

Hochstaet, H. (2005), "La autoridad oculta en el jardín de infantes." Revista 0 a 5. La educación en los primeros años, año 8, nº 61, 8-21.

Hochstaet, H. (2011): Los padres y el jardín. En OMEP (Coord) Educación Infantil. Estudios y prácticas. Volumen II Buenos Aires, OMEP - 12ntes. (pp.33-48)

Marotta, Elizabeth (2011) "El trabajo con las familias de bebés. Tejiendo redes para la crianza compartida.". En OMEP (Coord) Educación Infantil. Estudios y prácticas. Volumen I/ Buenos Aires, OMEP - 12ntes, 81-94.

Mayol Lassalle, Mercedes (2005), "Cuando el bebé ingresa al jardín maternal. El período de iniciación en la sala de 45 días a 12 meses". En C. Soto y R. Violante (comps.) En el jardín maternal. Investigaciones, reflexiones y propuestas. Buenos Aires, Paidós.

Meirieu, P. (1998), Frankenstein Educador. Barcelona, Laertes.

Moreau, L. y Windler, R. (2010), Sujetos de la educación inicial. Buenos Aires, Ministerio de Educación de la Nación. Aportes para el desarrollo curricular

Neufeld, M. R. (2010), "Familias y escuelas: la perspectiva de la antropología social". Revista Ensayos y Experiencias Año 7, No 36: Familias y escuelas. 3-13. Buenos Aires, Ediciones Novedades Educativas.

Nicastro, S. (2011), "Las relaciones del jardín y las familias: condiciones de posibilidad". En OMEP (Coord) Educación Infantil. Estudios y prácticas. Volumen II Buenos Aires, OMEP - 12ntes. (pp.81-94)

Perrenoud, P. (1996), La construcción del éxito y del fracaso escolar. Madrid, Morata. 
Pineau, P. (2001): "Por qué triunfó la escuela?, o la modernidad dijo: "Esto es educación", y la escuela respondió: "Yo me ocupo", en P. Pineau, I. Dussel y M Caruso: La escuela como máquina de educar. Tres escritos sobre un proyecto de la modernidad. Paidós, Buenos Aires (27-52).

Pulpeiro, S (2011), "El vínculo entre la familia y la escuela. ¿Comunicación o contacto?". En OMEP (Coord) Educación Infantil. Estudios y prácticas. Volumen II Buenos Aires, OMEP - 12ntes.

Siede, Isabelino A. (2015), Casa y jardín: complejas relaciones entre el Nivel Inicial y las familias. Rosario: Homo Sapiens Ediciones

Silberman, Silvia. (2010), "Entre padres y maestros". Revista Ensayos y Experiencias Año 7, No 36: Familias y escuelas. 45-55. Buenos Aires, Ediciones Novedades Educativas.

Soto, C. (2011), "Encuentros, escuchas y diálogos en el Jardín Maternal. El deseo de construir un espacio de encuentro cultural polifónico". En OMEP (Coord) Educación Infantil. Estudios y prácticas. Volumen I/ Buenos Aires, OMEP - 12ntes.

Soto, C. y Violante, R. (2005), Enseñar contenidos en el jardín maternal: una forma de compartir la crianza. En: C. Soto y R. Violante (comps.) En el jardín maternal. Investigaciones, reflexiones y propuestas. Buenos Aires, Paidós.

Soto, C. y Violante, R. (2010) Didáctica de la educación inicial. 1a ed. - Buenos Aires, Ministerio de Educación de la Nación, Aportes para el desarrollo curricular.

Terigi, F. y Perazza, R. (2006), Las Tensiones Del Formato Escolar en las Nuevas Configuraciones de la Relación Familia/ Comunidad/ Escuela: Una experiencia de educación infantil en la Ciudad de Buenos Aires, Journal of Education for International Development 2:3. Recuperado http://www.equip123.net/jeid/articles/4/LasTensionesDelFormatoEscolar.pdf $\quad$ (10 de Noviembre de 2017)

Waldmann, L. (2011), "Distintas maneras de ser niño". En OMEP (Coord) Educación Infantil. Estudios y prácticas. Volumen I/ Buenos Aires, OMEP - 12ntes.

Zabalza, M. (2000), Equidad y calidad en la educación Infantil. Una lectura desde el currículo. Ponencia en Simposio Mundial de Educación Infantil, Santiago de Chile.

\footnotetext{
Notas:

i Dada la variedad y diversidad de formatos familiares, cabe señalar que a lo largo del trabajo utilizamos la expresión "padres" indistintamente con la de "familia", solo por una cuestión de normalidad estadística.

ii En el trabajo mencionado (Fairstein, 2005b) desarrollamos esta idea y apuntamos que los roles del docente y de la pareja de padres se superponen incluso desde la dimensión psicológica -y no solo desde los objetivos pedagógicos- dado que ambos son representantes de lo social, que establece la triangularidad en el vínculo dual madre-hijo.

iii Para un desarrollo en profundidad de los cuatro modelos consultar Fairstein, 2005a y Fairstein, 2011. Allí profundizamos estas narrativas, a través de ejemplos concretos de la práctica, y analizamos el modo en que obstaculizan la tarea.

iv La necesidad de revisar y analizar la adecuación, a la educación infantil, de los modelos teóricos elaborados para otros niveles, ha sido abordada en Fairstein (2005b) en relación con las categorías de "alumno" y de "contenido curricular" (como se verá a continuación) y en Fairstein (2009) en relación con el modelo de planificación curricular y didáctica.

v Camilloni (2014) analiza el uso del triángulo como metáfora en la construcción de los discursos pedagógicos. Destaca su papel tanto para estructurar "el campo de significado postulando componentes y la naturaleza de las relaciones entre ellos" como para determinar y promover esquemas de prácticas de intervención. "El triángulo pedagógico y el triángulo didáctico son modelos muy poderosos en la
} 
configuración de los conceptos relacionados con la enseñanza. Son modelos basados sobre una representación en la que la estructura general permite presentar el desarrollo de un sistema en el que están definidos ab initio los componentes de la situación de enseñanza y sus relaciones. Se constituye sobre la base de una tríada que cuenta ya con historia propia en el campo de la teoría de la educación, y que ha servido para explicar y, en consecuencia, enseñar cuáles son esos componentes y cuál es la naturaleza de sus relaciones" (p.23)

vi Esta aclaración responde a si esta consideración implica negar la denominación de "contenido" al conocimiento del nivel inicial (Soto y Violante, 2010) La cuestión depende de los rasgos con los que se defina el concepto. Sin dudas, contenido es "todo lo que se enseña" (Basabe, Cols y Feeney, 2004) Pero más allá de esta definición genérica, la idea de "contenido" ha sido definida desde la didáctica y la teoría curricular en referencia a ciertos atributos que no son representativos del conocimiento que constituye, en su mayoría, el contenido de la educación infantil, por ejemplo: constituir una creación estrictamente pedagógica de un nuevo conocimiento (Basabe, Cols y Feeney, 2004), requerir una ayuda especificada para su aprendizaje (Coll y otros, 1994) y no poder ser transmitidos a través de experiencia cotidiana (Lundgren, 1992) Ahora bien, estas consideraciones no restan valor al contenido curricular de la educación infantil sino que solo alertan respecto de que la utilización del concepto -y toda la teoría didáctica y curricular acerca del tema- deben ser revisados en su adecuación antes de exportarlos a la educación infantil. De hecho, los conceptos centrales de estas disciplinas en relación con la cuestión del contenido curricular han sido elaborados en función de problemas que presenta su construcción principalmente en otros niveles educativos: cuestiones como la transposición didáctica, la descontextualización y recontextualización, o la traducción o conversión, la discusión en torno de las fuentes del contenido, la definición de criterios de selección, el debate acerca de los componentes, entre otros.

vii Para un desarrollo en profundidad de este modelo, remitimos al lector a Fairstein 2005b. Allí profundizamos esta argumentación y ofrecemos algunos ejemplos concretos de la práctica que permiten considerarlo de modo menos abstracto. 